Article

\title{
Applying the Theory of Planned Behavior to Examine Pro-Environmental Behavior: The Moderating Effect of COVID-19 Beliefs
}

\author{
Caterina Lucarelli (1), Camilla Mazzoli * and Sabrina Severini \\ Department of Management, Università Politecnica Delle Marche, Piazzale R. Martelli 8, 60121 Ancona, Italy; \\ c.lucarelli@univpm.it (C.L.); s.severini@univpm.it (S.S.) \\ * Correspondence: c.mazzoli@univpm.it; Tel.: +39-071-2207-254
}

Received: 10 November 2020; Accepted: 14 December 2020; Published: 17 December 2020

check for updates

\begin{abstract}
The COVID-19 pandemic and climate change issues present evident interdependencies which justify the spread of connected beliefs. We examine possible changes in individuals' pro-environmental behavior in light of this pandemic, using the Theory of Planned Behavior (TPB) framework. A questionnaire survey was submitted to the same sample of individuals, before and during the pandemic. Our evidence, based on Partial Least Squares Structural Equation Modeling (PLS-SEM), shows that the COVID-19 pandemic has not led to a weakening in TPB construct relationships, or in related Pro-Environmental Behavior (PEB). Conversely, through our Partial Least Squares-Multi-Group Analysis (PLS-MGA), we show that individuals with greater awareness of interdependencies between the COVID-19 and climate change exhibit both higher Intention and reinforced Pro-Environmental Behaviors. This finding reveals interesting policy implications in terms of innovative behavioral drivers that should be employed to steer public support towards climate-oriented initiatives.
\end{abstract}

Keywords: Theory of Planned Behavior; COVID-19; Partial Least Squares-Multi-Group Analysis; climate change emergency; pro-environmental behavior

\section{Introduction}

For some years now, climate change issues have become increasingly prominent in the international public debate and in political agendas. As a matter of fact, in the 15th edition of the Global Risk Report the World Economic Forum placed the Environment in the top 5 risks for the first time in history. Although climate-panel researchers from the United Nations are 95\% sure that the "dominant cause" of climate change is anthropogenic [1,2], human actions undertaken to address this issue are still scarce. One tool that has been suggested to counteract climate change relies on changing human behavior [3-6]. Going back to the 1970s, the idea that climate change issues could be addressed through the promotion of pro-environmental behaviors, namely through actions aimed at minimizing the negative human impact on the environment [7], has grown and gained acceptance. The simplest model proposed for analyzing pro-environmental behavior suggests that educating the public about environmental problems would lead to environmental awareness and concern, and consequently to pro-environmental behavior [8]. However, awareness and understanding alone cannot make it successful unless behavioral mechanisms steer individuals to accept their responsibility towards the environmental [9]. The fact remains that, since individuals perceive a psychological distance [10-12] between climate change and their own personal surroundings, this issue will continue to be considered of secondary importance in comparison to other priorities in people's daily lives [7]. This aspect becomes even more evident when pro-environmental behavior is hindered by catastrophic events, when emergency situations may lead people to review their perceptions of priorities. 
The 2020 COVID-19 pandemic provides a situation that allows us to analyze to what extent pro-environmental behavioral mechanisms are affected by health emergencies. On the one hand, some might think that dealing with a worldwide health emergency might detract attention from the fight against climate change which may no longer be a priority, thus leading to a decline in pro-environmental behavior. On the other hand, it is possible that COVID-19 could be reinforcing the idea that as long as we continue to ignore the environment, we will face pandemics and recurring disasters, thus supporting engagement in pro-environmental behaviors. In line with the latter view, several studies have found a positive relationship between climate change and the spread of Emerging Infectious Diseases (EIDs) (e.g., COVID-19, HIV, SARS-COV) [13-15].

The contribution of this paper lies in expanding pro-environmental behavior research in the context of the Theory of Planned Behavior (TPB) and in light of the COVID-19 pandemic. To this end, we perform Partial Least Squares Structural Equation Modeling (PLS-SEM) to test possible changes in the prediction of the Theory of Planned Behavior, by submitting a questionnaire to the same sample of individuals, before and during the pandemic. This is followed by Partial Least Squares-Multi-Group Analysis (PLS-MGA) to carry out a group analysis based on individuals' beliefs about the relationship between climate change and COVID-19.

To date, few researchers have considered the human behavioral responses to linkages between climate change and COVID-19 [16]. Ecker et al. [17] (p. 1) conducted an experiment in which they found that prioritizing the economic crisis triggered by COVID-19 and portraying climate change as an issue that should take a "back seat", effectively reduced climate-change concerns and diminished support for mitigation efforts. Similarly, Urban and Kohlova [18] analyzed the effects of the COVID-19 pandemic on actual choices regarding environmentally friendly delivery options; in their experiment, they found the effects of the COVID-19 crisis on pro-environmental behaviors to be ambiguous, at best. Nevertheless, neither of these studies used the Theory of Planned Behavior framework to analyze changes in eco-friendly behavior as a result of the pandemic.

Our evidence suggests that this health emergency has not led to a weakening in the TPB constructs and expected traditional relationships remain valid, especially concerning Pro-Environmental Behavior (PEB). By comparing groups of individuals who worry differently about the COVID-19 pandemic, we show in individuals with higher concern an increased engagement in issues related to the environment and thus, a strengthening of TPB constructs. We believe that the health emergency has shortened the perceived distance between environmental issues and people's personal microcosm. These findings, showing COVID-19 beliefs having a positive moderating effect on climate change issues, bring to light interesting policy implications in terms of the behavioral tools that could enhance public support in favor of ambitious policies aimed at overcoming the climate change emergency.

\section{Theoretical Framework and Research Hypotheses}

\subsection{Pro-Environmental Behavior}

Pro-environmental behavior can be defined as a "behavior that consciously seeks to minimize the negative impact of one's actions on the natural and built world" [19] (p. 240).

As is commonly accepted, pro-environmental behavior can be categorized into two broad dimensions, i.e., private sphere behaviors, on the one hand, and civic actions or environmental activism, on the other hand $[20,21]$. In this paper we adhere to the first perspective as it relates to the individual.

Pro-environmental behavior involves a number of different practices, such as recycling, conserving water, saving electricity, choice and use of transport, and consumption of green products, that can be grouped into three major categories: reduce, reuse, recycle.

As the awareness of the interdependence between human behavior and the environment has increased, several studies have endeavored to understand the factors that influence pro-environmental behavior. Li et al. [22] classified the determinants of pro-environmental behaviors into two main categories: external variables, such as social norms, cost, and convenience; and individual variables, 
which include demographic and psychological variables. Although early studies mainly used demographic and external factors to understand the mechanisms of pro-environmental behavior, later ones found psychological factors to be the most successful in predicting pro-environmental behaviors [23-25]. In particular, among the psychological variables, the most popular factor is attitude, namely the extent to which the behavior is assessed as favorable or unfavorable by the individual [24,26]. However, as $\mathrm{Li}$ et al. [22] suggest, there remains an incomplete understanding of how the pro-environmental behavior mechanisms are set in motion and how psychological variables interact with one another. On this point, Steg and Vlek [3] suggest that previous studies do not pay due attention to how contextual factors (such as infrastructures, technical facilities and the availability of products) and individuals' habits influence pro-environmental behavior. Moreover, these scholars propose three lines of research focused on individual motivations to engage in environmental behavior (i.e., perceived cost and benefits, moral and normative concerns, and affect) that could be integrated into a coherent framework. Not surprisingly, factors underlying environmental behavior have been studied from different theoretical perspectives (see [27]) in the field of environmental psychology. Some of the most widely used theories to explain pro-environmental behavior include: Theory of Reasoned Action, Theory of Planned Behavior, Schwartz's Norm Activation Theory [28], and Values-Beliefs-Norms Theory [29]. However, the Theory of Planned Behavior (TPB) has been used the most extensively to investigate the complex system of behavioral mechanisms which lead people from intentions to behaviors.

\subsection{Hypothesis onTheory of Planned Behavior and People's Response to Environmental Issues}

The Theory of Planned Behavior, first proposed by Ajzen in 1985 [30], has been widely applied to investigate the complex relationships between intentions and behaviors. The TPB represents a conceptual extension of the Theory of Reasoned Action (TRA), previously developed by Ajzen and Fishbein [31], which is based on the idea that any human behavior is affected by: Attitude which can be described as "the degree to which a person has a favorable or unfavorable evaluation or appraisal of the behavior in question" [32] (p. 188) and by the Subjective Norm which in [32] was defined as "the perceived social pressure to perform or not to perform the behavior" (p. 188). In other terms, Attitude is a personal factor which refers to a person's evaluation of the behavior while Subjective Norm is the perceived opinions of significant others who are close/important to an individual and who influence their decision-making (e.g., relatives, close friends, co-workers/colleagues, or business partners). For sake of the readers, when we refer to the TPB constructs, we label these expressions with initial capital letters.

TPB takes into consideration a further variable able to contribute to predicting the choices that individuals would be willing to carry out: Perceived Behavioral Control. In fact, while the Theory of Reasoned Action focuses solely on volitional personal/social factors when explaining an individual's Intention formation, the Theory of Planned Behavior also examines the expectation about "the ease or difficulty in implementing a certain behavior" [32] which is a reflection of people's beliefs or "confidence in their ability to perform" a certain action [32] (p. 457), as well as an indication of the "available resources and opportunities." The applicability of TRA has been questioned because, in some cases, it is not enough to predict an individual's intention/behavior, especially when the latter might be determined by non-volitional factors (e.g., resources) [30]. Another extension of TRA, conceptually similar to TPB, is the integrative model (IM) of behavioral prediction, proposed by Fishbein and Yzer [33]. It incorporates the self-efficacy construct, which refers to one's perceived ability to perform behavior in the presence of some barriers, instead of the Perceived Behavioral Control variable alone. Because of its strong predictive power, TPB has been widely utilized as a model to predict intentions and behaviors in different areas such as food consumption and health-related behavior [34]. However, especially in the field of environmental science, TPB is increasingly being advocated as a key theory for predicting and promoting a variety of Pro-Environmental Behaviors [22]. According to the study in [35] the primary research topics where TPB is applied are: waste management, 
green consumption, climate and environment, saving and conservation, and sustainable transportation. Previous literature dealing with TPB in the environment discourse has demonstrated that Attitudes, Subjective Norms, and Perceived Behavioral Control play key roles in shaping the Intention to engage in Pro-Environmental Behaviors [9] and such mechanisms can be further reinforced by people's moral obligation to perform PEB [36]. Moreover, some researchers have proposed an Extended Theory of Planned Behavior (ETPB), adding other predictors of behaviors to the original TPB model, thereby improving, in some cases, the predictive power of Intentions [36].

Thus, the first group of hypotheses (H1) is explored to validate well-known TPB constructs, on our pre- and post-COVID-19 samples. Under the premises of the traditional TPB presented above, this study hypothesizes that:

Hypothesis 1a (H1.a). There is a positive relationship between individuals' Attitudes toward climate change and their Intentions.

Hypothesis $1 \mathbf{b}$ (H1.b). Subjective norms are directly and positively associated with individuals' Intentions.

Hypothesis 1c (H1.c). Perceived Behavioral Control is directly and positively associated with individuals' Intentions.

Hypothesis 1d (H1.d). Behavioral Intentions are directly and positively associated with individuals' PEB.

\subsection{Hypothesis on Individuals' Beliefs about the Relationship between Climate Change and COVID-19}

Our aim is to explore possible variations in the predictions of the TPB model due to concern and worries induced by the pandemic, as shown in Figure 1 which illustrates our research framework. Because individuals may behave differently depending on their personal perception of the problem, we hypothesize that those who are more sensitive to possible COVID-19-climate change interdependencies will increase their level of sustainable climate-related Intentions and take more environmentally friendly actions. Thus, the second group of hypotheses (H2) aims to test the possible moderation role of COVID-19 in different groups of individuals, as follows:

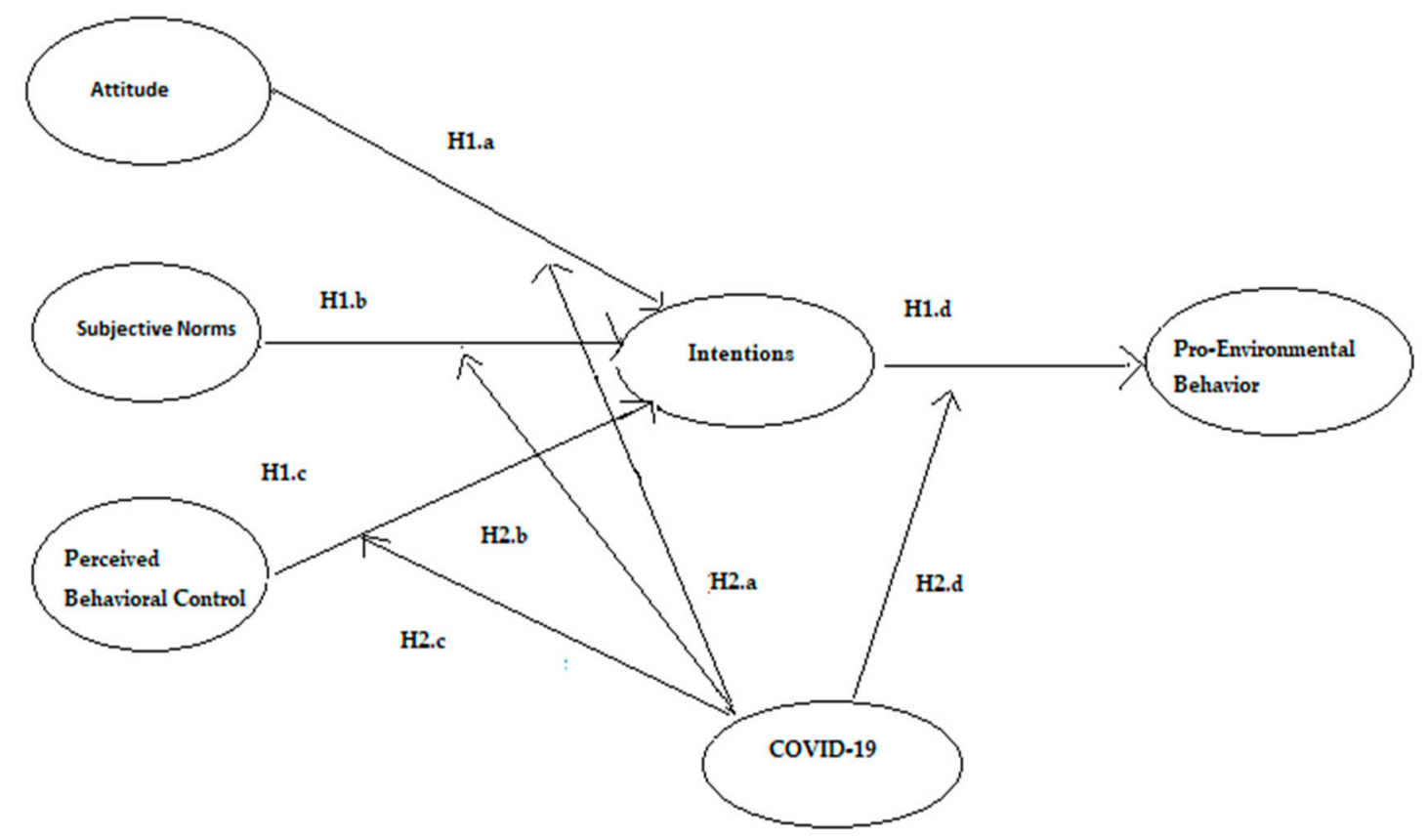

Figure 1. Proposed research framework. 
Hypothesis 2a (H2.a). Individuals who are more sensitive to possible COVID-19-climate change interdependencies show a greater positive relationship between Attitude and Intentions, compared to those who are not.

Hypothesis $\mathbf{2 b} \mathbf{~ ( H 2 . b ) . ~ I n d i v i d u a l s ~ w h o ~ a r e ~ m o r e ~ s e n s i t i v e ~ t o ~ p o s s i b l e ~ C O V I D - 1 9 - c l i m a t e ~ c h a n g e ~}$ interdependencies show a greater positive relationship between Subjective Norms and Intentions, compared to those who are not.

Hypothesis 2c (H2.c). Individuals who are more sensitive to possible COVID-19-climate change interdependencies show a greater positive relationship between Perceived Behavioral Control and Intentions, compared to those who are not.

Hypothesis 2d (H2.d). Individuals who are more sensitive to possible COVID-19-climate change interdependencies show a greater direct positive relationship between behavioral Intentions and PEB, compared to those who are not.

\section{Methodology}

\subsection{Research Instrument and Data Collection}

In this paper we perform an empirical validation of the TPB framework on a sample of university students, as a part of a larger, cross-European research project funded by EIT Climate-KIC in 2019-2020. University students are important stakeholders in the climate change issue for several reasons: they are those who will be affected the most by climate change in the future $[37,38]$ and they already have-or will more easily gain - the technical and specialized knowledge background that is needed to develop suitable solutions to tackle climate change $[39,40]$.

On this premise, we sampled students enrolled in each year of a three-year Bachelor's degree program in Economics. The initial sample of students was composed of $n=1292$ individuals, total; these were broken down into: $n=547$ first year students, $n=317$ second year students, and $n=428$ third year students. In December 2019 a paper version of a TPB questionnaire was submitted to students physically present and attending lessons; the survey was conducted on-site and 524 responses were completed and returned to the researchers after classes. During the Italian lockdown period (March-April 2020) we submitted, via e-mail, to the same students previously surveyed in December, a post-COVID-19 questionnaire, to which 239 responses were received. It was an expanded version of the first one and included a set of questions dealing with post-COVID-19 behavioral mechanisms related to environmental issues. We acknowledge the limitations inherent in comparing the responses obtained from a paper version (pre-COVID-19) and those from a digital version (post-COVID-19) of the questionnaire. The students' degree of involvement and sense of responsibility when taking part in the online survey appear to be much lower than when the survey was administered physically, helping to explain the lower number of responses to the post-COVID-19 questionnaire. The fact that the COVID-19 pandemic was unforeseeable in December 2019 coupled with the lockdown restrictions of March-April 2020 made these limitations unavoidable.

Both questionnaires are identical and consist of two parts. Section A contains demographic information about the respondents. Section B includes questions designed to measure Attitudes towards climate change, Subjective Norms, Perceived Behavioral Control, Intention, and Pro-Environmental Behavior. The items that measured all latent variables were adopted from Masud et al. [9]. The final version of the questionnaire is reported in the Appendix (see Table A1). Moreover, the post-COVID-19 questionnaire also includes a Section $C$ which contains questions related specifically to COVID-19 (see Table A2 in Appendix A). Respondents were asked to express their opinion on some statements provided by agreeing or disagreeing, based on a 7-point Likert-type scale, with 1 indicating "strongly disagree" and 7 "strongly agree." In order to minimize possible response bias, the words "there are no right or 
wrong answers" were emphasized in the covering letter. In completing the questionnaire anonymously, the voluntary participants were assured that all individual responses would be kept confidential.

By adopting Partial Least Squares Structural Equation Modeling (PLS-SEM) our goal is to verify whether predictions of behavioral Intention to adopt Pro-Environmental Behavior, suggested by the TPB model, have remained unchanged after the start of the COVID-19 pandemic. We also aim to investigate any possible variation with respect to the main intention-behavior mechanisms that individual COVID-19 experiences and/or beliefs might have produced. To this end, a Partial Least Squares-Multi-Group Analysis (PLS-MGA) was conducted in order to carry out a group analysis based on the responses that individuals provided to a set of specific questions related to the COVID-19 pandemic (see Section 4.4).

\subsection{Data Analysis (PLS-SEM)}

Structural equation modeling (SEM) has grown in popularity across a variety of scientific disciplines, especially in social science studies, over the last decade [41]. Structural equation modeling allows the researcher to statistically examine "whether a hypothesized model is consistent with the data collected to reflect [the] theory" [42] (p. 34). The two major approaches to structural modeling are the covariance-based SEM (CB-SEM) and variance-based SEM (PLS-SEM) [43,44]. Although both approaches allow a statistical examination of "the cause-effect relations between latent constructs" [41] (p. 139), they differ in terms of assumptions, outcomes, and estimation procedures. While the CB-SEM follows a maximum likelihood (ML) estimation procedure and aims at "reproducing the covariance matrix [i.e., minimizing the difference between the observed and estimated covariance matrix], without focusing on explained variance" [41] (p. 139), PLS-SEM uses a regression-based ordinary least squares (OLS) estimation method with the goal of explaining the latent construct variance by "minimizing the error terms [and maximizing] the R2 values of the (target) endogenous constructs" [45] (p. 14). In addition, the PLS-SEM imposes less restrictive requirements and assumptions in terms of large sample sizes and the normality of the data while conserving robustness in estimations [46]. Since this study deals with non-normality issues, we consider variance-based PLS-SEM a more suitable and robust method for investigating possible changes in the pro-environmental behaviors. Following the suggested two-stage analytical procedures of the PLS-SEM approach, the next section presents both the results of the measurement model (convergent and discriminant validity of measures) and the structural model (testing the hypothesized relationship). The Difference-in-difference (DID) model does not fit well in our case since it is not possible to make any assumptions that would lead us to believe that some individuals have not been treated (for COVID-19). Moreover, dividing the group into those who have had COVID-19 symptoms and those who have not would make the sample in the first group excessively small.

\section{Results}

\subsection{The Socio-Demographic Characteristics of the Respondents}

Table 1 summarizes the socio-demographic characteristics of the two samples of students participating in this survey, before $(n=524)$ and after $(n=239)$ manifestation of the pandemic, based on Section A responses. We ran an independence test to show that the pre- and post-COVID-19 samples are non-statistically different; this allows us to assume that differences between samples are mainly due to the pandemic situation. The percentages of male and female respondents are almost equal $(50.38 \%$ and $49.62 \%$, respectively, in the pre-COVID sample and $45.62 \%$ and $54.39 \%$ in the post-COVID sample). In terms of age, there is a predominance of young people between 18 and 20 years of age, due to the sampling criteria based on university students attending a 3-year degree program in Economics. In both samples, the majority of the respondents' families have completed their secondary education, approximatively $20 \%$ of them have a Bachelor's or a Master's degree, and only $10 \%$ have completed a postgraduate specialization. Moreover, the majority of respondents said they were not too optimistic 
about the future. In terms of volunteer activities, fewer than $20 \%$ of the respondents were involved. Most of the respondents ( $80.91 \%$ in the pre-COVID sample and $87.44 \%$ in the post-COVID sample) had not been harmed by climatic events.

Table 1. Sample profiles of the respondents.

\begin{tabular}{|c|c|c|c|c|c|}
\hline \multirow[b]{3}{*}{ Item } & \multirow[b]{3}{*}{ Group } & \multirow{2}{*}{\multicolumn{2}{|c|}{$\begin{array}{c}\text { Pre-COVID-19 } \\
n=524\end{array}$}} & \multirow{2}{*}{\multicolumn{2}{|c|}{$\begin{array}{c}\text { Post-COVID-19 } \\
n=239\end{array}$}} \\
\hline & & & & & \\
\hline & & Frequency & Percentage & Frequency & Percentage \\
\hline \multirow{2}{*}{ Gender } & Male & 264 & 50.38 & 109 & 45.61 \\
\hline & Female & 260 & 49.62 & 130 & 54.39 \\
\hline \multirow{3}{*}{ Age } & $19-20$ & 331 & 63.17 & 94 & 39.33 \\
\hline & $21-23$ & 174 & 33.2 & 138 & 57.74 \\
\hline & $>24$ & 19 & 3.63 & 7 & 2.93 \\
\hline \multirow{5}{*}{ Family education level } & 8th Grade & 42 & 8.02 & 22 & 9.2 \\
\hline & $\begin{array}{l}\text { High school } \\
\text { diploma }\end{array}$ & 254 & 48.47 & 90 & 37.66 \\
\hline & Bachelor's degree & 68 & 12.97 & 39 & 16.32 \\
\hline & Master's degree & 108 & 20.61 & 64 & 26.78 \\
\hline & $\begin{array}{l}\text { Postgraduate } \\
\text { Degree }\end{array}$ & 52 & 9.93 & 24 & 10.04 \\
\hline \multirow{4}{*}{$\begin{array}{l}\text { Attitude towards the } \\
\text { future }\end{array}$} & Pessimistic & 38 & 7.25 & 13 & 5.44 \\
\hline & Not too optimistic & 257 & 49.04 & 124 & 51.88 \\
\hline & Optimistic & 197 & 37.59 & 91 & 38.08 \\
\hline & Very optimistic & 32 & 6.12 & 11 & 4.6 \\
\hline \multirow{2}{*}{$\begin{array}{l}\text { Performs voluntary } \\
\text { activities }\end{array}$} & No & 439 & 83.77 & 194 & 81.17 \\
\hline & Yes & 85 & 16.23 & 45 & 18.83 \\
\hline \multirow{2}{*}{$\begin{array}{l}\text { Has suffered damage } \\
\text { from climatic events }\end{array}$} & No & 424 & 80.91 & 209 & 87.44 \\
\hline & Yes & 100 & 19.09 & 30 & 12.56 \\
\hline
\end{tabular}

\subsection{Measurement Model Analysis}

Table 2 summarizes the descriptive statistics that include the number of items, as well as the mean, standard deviation, and correlation matrix of all the latent variables. The mean value for Intention was relatively lower than all the other variables, especially in the pre-COVID-19 sample. Notably, the mean values of all the constructs are moderately higher in the post-COVID-19 sample, showing that climate issues are becoming increasingly relevant. In particular, we find a statistically significant difference in the means of Attitude and Pro-Environmental Behavior (5\% and 10\%, respectively) between the pre-COVID and post-COVID samples. The correlations range from 0.328 (i.e., Pro-Environmental Behavior and Attitude in the pre-COVID-19 sample) to 0.773 (i.e., Behavioral Intentions and Subjective Norms in the post-COVID-19 sample). In Table 3 we report the results of the internal consistency reliability and indicator reliability of the models test [41]. Cronbach's $\alpha$ is the most widely used criterion to measure the internal consistency of the indicators measuring a given construct [47]. All of the variables, except Attitude, achieved a Cronbach's $\alpha$ value of more than 0.7 , indicating that all the items were reliable. This evidence is also confirmed by the Dillon-Goldstein rho and $\mathrm{rho}_{\mathrm{A}}$ [48] whose values for all of the constructs were higher than 0.7 , providing evidence of good internal consistency. Next, we assessed the convergent validity and discriminant validity of the measurement models. To achieve convergent validity, the Average Variance Extracted (AVE) value should be higher than 0.50. As depicted in Table 3, the values of Average Variance Extracted (AVE) were close to or above 0.5 in our samples, indicating an acceptable convergent validity. The discriminant validity is the degree to which a construct is truly different from other constructs. We assessed the discriminant validity using the Heterotrait-Monotrait (HTMT) ratio, preferring it over other assessment methods, such as 
the Fornell-Larcker criterion [49]. As shown in Table 4, the Heterotrait-Monotrait ratios of correlations were lower than 0.85 in the two samples, indicating a high validity for the measurement models.

Table 2. Descriptive statistics and correlation matrix of studied constructs.

\begin{tabular}{|c|c|c|c|c|c|c|c|c|c|c|c|c|c|c|c|}
\hline & \multicolumn{8}{|c|}{ Pre-COVID-19 } & \multicolumn{6}{|c|}{ Post-COVID-19 } & \\
\hline & Item & Mean & SD & & & & & & Mean & SD & & & & & \\
\hline ATE & 4 & 5.251 & 0.943 & 1 & & & & & 5.434 & 0.916 & 1 & & & & \\
\hline $\mathrm{SN}$ & 5 & 5.054 & 1.069 & 0.616 & 1 & & & & 5.062 & 0.961 & 0.660 & 1 & & & \\
\hline РBC & 4 & 4.992 & 1.223 & 0.465 & 0.680 & 1 & & & 5.054 & 1.085 & 0.488 & 0.661 & 1 & & \\
\hline INT & 6 & 4.734 & 1.105 & 0.505 & 0.711 & 0.662 & 1 & & 4.789 & 1.120 & 0.588 & 0.773 & 0.686 & 1 & \\
\hline PEB & 6 & 4.869 & 1.092 & 0.328 & 0.467 & 0.435 & 0.556 & 1 & 5.019 & 1.060 & 0.470 & 0.576 & 0.549 & 0.620 & 1 \\
\hline
\end{tabular}

Note: ATE: Attitude; SN: Subjective Norms; PBC: Perceived Behavioral Control; INT: Intention; PEB:

Pro-Environmental Behavior; SD: Standard Deviation.

Table 3. Reliability and validity.

\begin{tabular}{ccccccccc}
\hline & \multicolumn{4}{c}{ Pre-COVID-19 } & \multicolumn{5}{c}{ Post-COVID-19 } \\
\hline Variables & CA & DG & rho $_{\text {A }}$ & AVE & CA & DG & rho $_{\text {A }}$ & AVE \\
\hline ATE & 0.577 & 0.750 & 0.621 & 0.443 & 0.669 & 0.792 & 0.729 & 0.504 \\
SN & 0.768 & 0.844 & 0.805 & 0.525 & 0.748 & 0.832 & 0.799 & 0.505 \\
PBC & 0.807 & 0.874 & 0.812 & 0.634 & 0.815 & 0.879 & 0.830 & 0.645 \\
INT & 0.827 & 0.876 & 0.854 & 0.548 & 0.847 & 0.889 & 0.878 & 0.580 \\
PEB & 0.717 & 0.809 & 0.751 & 0.423 & 0.723 & 0.812 & 0.741 & 0.423 \\
\hline
\end{tabular}

Note: ATE: Attitude; SN: Subjective Norms; PBC: Perceived Behavioral Control; INT: Intention; PEB: Pro-Environmental Behavior; CA: Cronbach's Alpha; DG rho-Dillon-Goldstein's rho; rho ${ }_{\mathrm{A}}-$ Dijkstra and Henseler (2015); AVE—Average Variance Extracted.

Table 4. Discriminant validity.

\begin{tabular}{cccccc}
\hline \multicolumn{5}{c}{ Pre-COVID-19 } \\
& ATE & SN & PBC & INT & PEB \\
\hline ATE & - & & & \\
SN & 0.379 & - & & & \\
PBC & 0.216 & 0.462 & - & & \\
INT & 0.255 & 0.505 & 0.438 & - & - \\
PEB & 0.107 & 0.218 & 0.189 & 0.309 & \\
\hline \multicolumn{7}{c}{ Post-COVID-19 } \\
Heterotrait-Monotrait Ratio (HTMT) & PEB \\
\hline ATE & - & SN & PBC & INT & \\
SN & 0.436 & - & & & \\
PBC & 0.238 & 0.437 & - & & - \\
INT & 0.345 & 0.598 & 0.470 & - & \\
PEB & 0.221 & 0.332 & 0.301 & 0.385 & \\
\hline
\end{tabular}

Note: ATE: Attitude; SN: Subjective Norms; PBC: Perceived Behavioral Control; INT: Intention; PEB: Pro-Environmental Behavior.

\subsection{Path Analysis}

Table 5 reports the estimated goodness-of-fit $(\mathrm{GoF})$ values of the structural model for both the pre-COVID-19 (0.473) and the post-COVID-19 (0.523) samples. Both GoF are larger than the suggested value of 0.36 [50], indicating a good fit level for the model. Estimation results for the TPB model predicting behavioral Intention and Pro-Environmental Behavior, in the pre-COVID-19 sample, are provided in Table 5. In line with the findings of [9], Attitude towards climate change $(\beta=0.084$, $p<0.005)$, Subjective Norms $(\beta=0.438, p<0.001)$, and Perceived Behavioral Control $(\beta=0.325, p<0.001)$ 
have a positive and significant influence on behavioral Intention to adopt PEB. Moreover, Intention significantly affects Pro-Environmental Behavior $(\beta=0.556, p<0.001)$. As expected, the theoretical framework of TPB continues to be verified also in the post-COVID-19 sample. Attitude toward climate change $(\beta=0.110, p<0.005)$, Subjective Norms $(\beta=0.503, p<0.001)$, and Perceived Behavioral Control $(\beta=0.300, p<0.001)$ are positive contributors to Intention. Furthermore, the Pro-Environmental Behavior $(\beta=0.620, p<0.001)$ is positively conditioned by the level of Intentions. Our evidence suggests that the event of the pandemic did not negatively affect the Intentions/sustainable actions towards climate change. Such a finding is consistent with studies demonstrating that behavioral traits tend to remain stable over time and are invariant with regards to life-adverse events.

Table 5. Hypotheses testing results.

\begin{tabular}{|c|c|c|c|c|c|}
\hline \multirow[b]{2}{*}{ Hypothesis } & \multirow[b]{2}{*}{ Relationship } & \multicolumn{2}{|c|}{ Pre-COVID-19 } & \multicolumn{2}{|c|}{ Post-COVID-19 } \\
\hline & & Std $\beta$ & $p$-Value & Std $\beta$ & $p$-Value \\
\hline H1.a & $\mathrm{ATN} \rightarrow \mathrm{INT}$ & 0.084 & 0.044 * & 0.110 & 0.044 * \\
\hline H1.b & $\mathrm{SN} \rightarrow \mathrm{INT}$ & 0.438 & $0.000 * * *$ & 0.503 & $0.000^{* * *}$ \\
\hline H1.c & $\mathrm{PBC} \rightarrow \mathrm{INT}$ & 0.325 & $0.000^{* * *}$ & 0.300 & $0.000^{* * *}$ \\
\hline H1.d & $\mathrm{INT} \rightarrow \mathrm{PEB}$ & 0.556 & $0.000^{* * *}$ & 0.620 & $0.000^{* * *}$ \\
\hline
\end{tabular}

Note: ATE: Attitude; SN: Subjective Norms; PBC: Perceived Behavioral Control; INT: Intention; PEB: Pro-Environmental Behavior. ${ }^{*}, *$, and ${ }^{* * *}$ denote significance at the $10 \%, 5 \%$, and $1 \%$ levels, respectively.

However, depending on personal beliefs regarding possible COVID-19-climate change interdependencies, some groups of people may show the effect of the latent variables on Intention and on Pro-Environmental Behavior. In the next section, we delve more deeply into the possible role that the COVID-19 pandemic may have played with respect to awareness of climate change problems in different groups of individuals.

\subsection{Multi-Group Analysis}

We use Multi-Group Analysis (PLS-MGA) to test the possible moderating effect of COVID-19 beliefs in the TPB framework. Multi-group analysis is generally regarded as a special case of modelling continuous moderating effects [49,51]. The comparison of group-specific effects entails the consideration of a categorical moderator variable which "affects the direction and/or strength of the relation between an independent or predictor variable and a dependent or criterion variable" [52] (p. 1174). To examine this possibility, we constructed two dummy variables, RU (relationship_urgent) and RI (relationship_improved), as shown in Table 6, that identify individuals with a higher level of sensitivity to possible relationships and interdependencies between climate change and COVID-19. The variable RU is valued one (1) if the respondent has chosen option one to CC1 (Yes, there is a relationship between COVID-19 and climate change) and CC2 (Climate change is more urgent after COVID-19) question, and zero (0) otherwise. The variable RI is valued one (1) if the respondent has chosen option one to CC1 (Yes, there is a relationship between COVID-19 and climate change) and CC3 (The COVID-19 lockdown showed us that by changing our habits we can actually improve the climate problem), and zero (0) otherwise.

Table 7 presents the $p$-values of the path coefficients between the two groups. The results indicate that the effect of Intention on Pro-Environmental Behavior among the respondents is one (1) or zero (0) to the question RU was statistically significant. In the first case, the path coefficient appeared to be higher; namely, those who have assessed the climate problem as urgent and see a high impact of COVID-19 on the climate show a greater relationship between Intention and Pro-Environmental Behavior. Similarly, the effect of Perceived Behavioral Control on Intention among the RI $=1$ group was significantly higher than that of the other group. In other terms, our results suggest that although 
the TPB path model continues to be verified even after the COVID-19 pandemic, some differences between path parameters that are estimated for different subpopulations can be highlighted.

Table 6. Description of the moderating variables.

\begin{tabular}{ll}
\hline \multicolumn{1}{c}{ COVID-19 Moderating Variables } & \\
\hline CC2-Option 1 (Climate change is more urgent after & RU \\
COVID-19) & \\
and & \\
CC1-Option 1 (Yes, there is a relationship between & \\
COVID-19 and climate change) & RI \\
\hline CC3-Option 1 (The COVID-19 lockdown showed us & \\
that by changing our habits we can actually improve & \\
the climate problem) & \\
and & \\
CC1-Option 1 (Yes, there is a relationship between & \\
COVID-19 and climate change) &
\end{tabular}

Figure 2 provides a graphical representation of the estimated path coefficient of both groups of hypotheses. Although the temporal proximity of the two questionnaires submitted may have driven the results of the PLS-SEM, the changes that occurred with the pandemic event were a definitive exogenous shock to human lifestyles. Therefore, the PLS-MGA results support our belief that the severity of COVID-19 has played a significant moderating role in the behavioral Intention and Pro-Environmental Behavior.

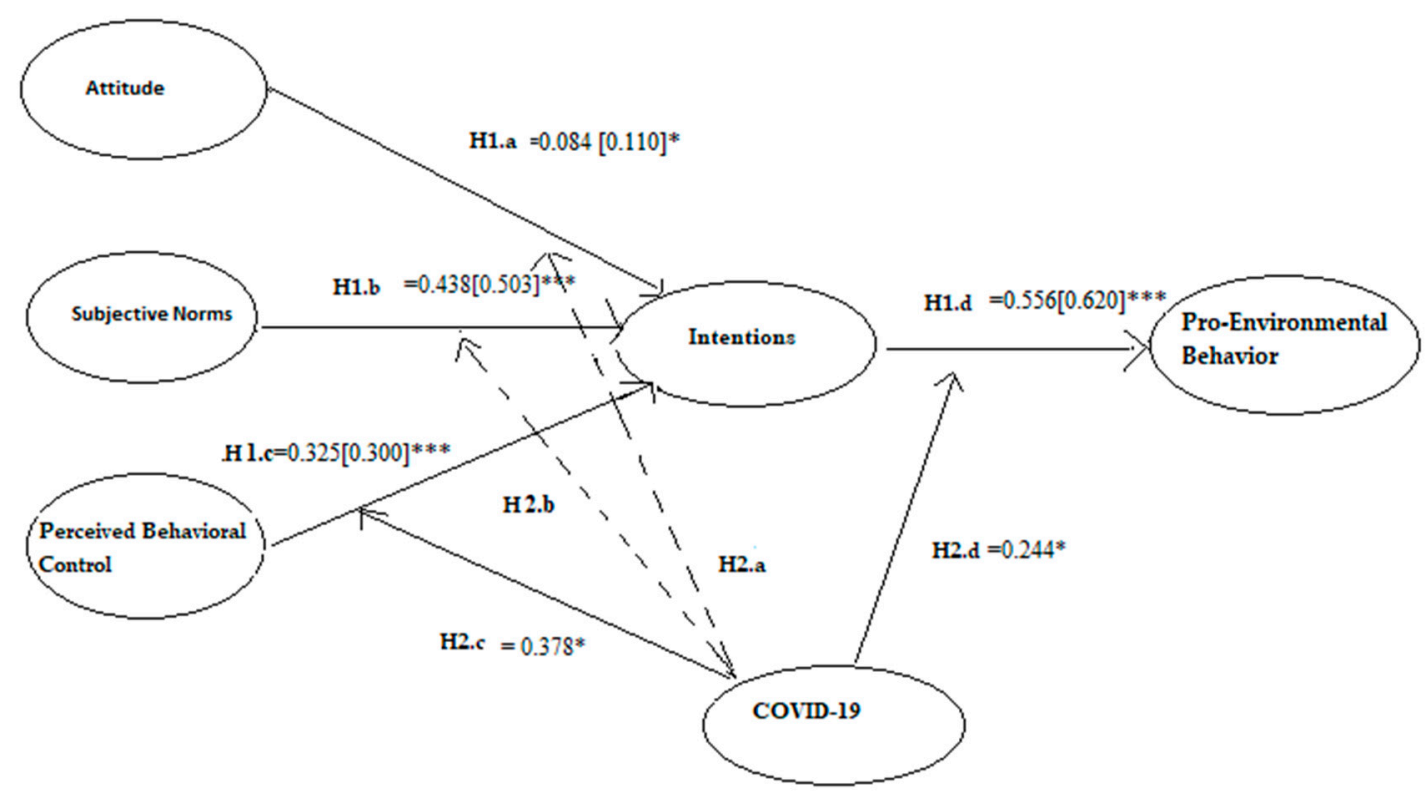

Figure 2. Estimated path coefficients. Note: Significant path $\rightarrow$; Non-significant path. For the first group of hypotheses (H1) std $\beta$ of Pre COVID-19 (std $\beta$ of Post COVID-19 in parenthesis) are presented. For the second group of hypotheses $(\mathrm{H} 2)$ significant path coefficient difference is presented. * ${ }^{* *}$, and *** denote significance at the $10 \%, 5 \%$, and $1 \%$ levels, respectively. 
Table 7. Moderating effect of COVID-19.

\begin{tabular}{|c|c|c|c|c|c|c|c|c|c|c|c|}
\hline HP & Relationship & $\begin{array}{c}\text { Path Coeff } \\
\text { RU }=0\end{array}$ & $\begin{array}{c}\text { Path Coeff } \\
\text { RU }=1\end{array}$ & $\begin{array}{c}\text { Path Coeff } \\
\text { Diff }\end{array}$ & $p$-Value & & $\begin{array}{c}\text { Path Coeff } \\
\text { RI }=0\end{array}$ & $\begin{array}{c}\text { Path Coeff } \\
\text { RI = } 1\end{array}$ & $\begin{array}{c}\text { Path Coeff } \\
\text { Diff }\end{array}$ & $p$-Value & \\
\hline H2.a & $\mathrm{ATE} \rightarrow \mathrm{INT}$ & 0.087 & -0.179 & 0.266 & 0.464 & & 0.207 & 0.204 & 0.003 & 0.838 & \\
\hline $\mathrm{H} 2 . \mathrm{b}$ & $\mathrm{SN} \rightarrow \mathrm{INT}$ & 0.483 & 0.999 & 0.516 & 0.258 & & 0.547 & 0.215 & 0.332 & 0.155 & \\
\hline H2.d & $\mathrm{INT} \rightarrow \mathrm{PEB}$ & 0.528 & 0.772 & 0.244 & 0.127 & * & 0.585 & 0.560 & 0.025 & 0.930 & \\
\hline
\end{tabular}

Note: ATE: Attitude; SN: Subjective Norms; PBC: Perceived Behavioral Control; INT: Intention; PEB: Pro-Environmental Behavior. RU = 1 if the respondent has chosen option one to the CC1 (Yes, there is a relationship between COVID-19 and climate change) and CC2 (Climate change is more urgent than COVID-19); RI = 1 if the respondent has chosen option one to CC1 (Yes, there is a relationship between COVID-19 and climate change) and CC3 (The COVID-19 lockdown showed us that by changing our habits we can actually improve the climate problem). ${ }^{*}, * *$, and ${ }^{* * *}$ denote significance at the $10 \%, 5 \%$, and $1 \%$ levels, respectively. 


\section{Discussion and Conclusions}

Even though scientific evidence identifies humans as primarily responsible for the climate change emergency, pro-environmental actions remain scarce. Moreover, there has been little research focusing on how people's willingness to change their environmental behavior is affected by emergencies and crises $[53,54]$. To the best of our knowledge, no existing study has specifically addressed if and how individuals have changed their Pro-Environmental Behavior because of the spread of beliefs induced by the COVID-19 pandemic using the TPB framework; this represents the main contribution of our research. While it is possible that the COVID-19 experience has acted as a "trial run" for future engagement in the global climate crisis, it is also plausible that Pro-Environmental Behavior needs to take a "back seat" (e.g., [17] (p. 1), [55]). Recent studies have highlighted that the current COVID-19 pandemic has represented a learning experiment on how to cope with climate change [56], given that both situations suffer from the same behavioral biases [57-60].

According to our results, no relevant variations in environmental Intentions/Pro-Environmental Behavior are found between the pre- and post-COVID-19 cases, confirming the expected traditional relationships between constructs of the TPB. Nevertheless, an in-depth MGA-PLS analysis, based on the sensitivity of different groups of individuals to the COVID-19/climate change interconnections, revealed a moderation role of the pandemic on the behavioral Intention and the Pro-Environmental Behavior.

Our findings recall existing literature regarding the way people perceive and respond to different threats. As a first consideration, whether a threat is perceived as "imminent" changes reactions to it dramatically: the COVID-19 pandemic has clearly demonstrated that societies pay a high price when facing an imminent threat, both financially and in terms of restrictions, such as lockdowns [61]. In addition to this, when faced with a threat, people tend to rely on their own past experiences with similar events to determine the ease with which they will cope. This effect is called availability heuristic [62]. The perceived distance of events considered remote is considerably shortened when external phenomena generate tragic consequences in people's personal microcosm. Our evidence opens up important parallels for policy design. Since both emergencies pose systemic risks to human perspectives and both require restrictive measures, the COVID-19 emotive memory could be used to get citizens on board and foster the development of participatory planning tools [62-64]. In particular, the above-mentioned psychological drivers (perceived imminence of threat and availability heuristic) might be exploited to enhance public support in favor of ambitious climate policies. Accordingly, policymakers should reframe information and awareness campaigns to reduce the psychological distance between the climate change issue and people's individual microcosm.

This research has some limitations that we consider when discussing and interpreting the findings. First, the temporal proximity of the two questionnaires administered may have affected the results. In fact, changes in behavior typically take a long time to translate into concrete actions. Nevertheless, we believe that the spread of the pandemic was pervasive enough to assume that between December 2019 and March/April 2020 our lives were structurally revolutionized.

Second, we acknowledge the limitations of comparing responses to a paper-based survey and an online questionnaire, even if no research alternatives were practically possible.

Third, our evidence is limited to a sample of university students who, despite having endured the greatest consequences of past and current carelessness towards the environment, provide only a partial picture of reality. Therefore, future studies should consider other samples in order to have a better basis for comparison. Within the European project mentioned above, further research is already being undertaken in order to deepen the complex awareness-intention-action mechanisms in a sample of investors and entrepreneurs that will be provided by the project stakeholders. We therefore expect that further and deeper insights will emerge in the future regarding the behavioral patterns underlying pro-environmental actions and on the moderating role that COVID-19 has been proven to exert on those patterns.

Finally, this study shares some limitations with other research that uses self-reported behavior; prior meta-analytical studies of TPB suggest that Intention is not a robust predictor of actual behavior [65]. 
As a matter of fact, the correspondence between self-reported behavior and actual or observed behavior is not always verified $[36,66]$. To overcome the limitations related to self-reported behaviors, a follow up study on the above-mentioned group of professionals has already been scheduled for 2021 to test for actual pro-environmental behaviors that sampled investors and firms will have adopted in time.

Author Contributions: Conceptualization, C.L., C.M. and S.S.; methodology, S.S.; software, S.S.; validation, C.L.; formal analysis, C.M.; investigation, C.M.; data curation, S.S.; writing-original draft preparation, S.S.; writing-review and editing, C.L., C.M. and S.S.; supervision, C.L. All authors have read and agreed to the published version of the manuscript.

Funding: This research received no external funding.

Acknowledgments: This research was realized within the European project Circular Learning Hub (CL-hub): A learning hub for the engagement and ecosystem transition towards circular thinking funded by EIT Climate-KIC for 2019-2020. Views are those of the authors and do not reflect the views of EIT Climate-KIC. EIT Climate-KIC provides no warranties or representations as to the completeness, accuracy or suitability for any purpose of this paper's content. Authors are deeply grateful to Amadio Sacripanti (IT graduate assistant at the Department of Management, Università Politecnica delle Marche) for his constant and vital technical support in the implementation and administration of the online questionnaire.

Conflicts of Interest: The authors declare no conflict of interest.

\section{Appendix A}

Table A1. Questionnaire from Masud et al. [9].

\begin{tabular}{l}
\hline Items \\
Attitudes \\
The environment is in danger because of global climate change \\
Current global warming is a natural and not manmade phenomenon \\
Climate change damages the natural environment and wildlife \\
I'm willing to pay a certain amount to reduce the impact of climate change \\
Subjective Norms \\
My family/peers often discuss climate change or global warming. \\
I'd feel guilty if climate change had a negative impact \\
People should do everything they can to reduce the impact of climate change \\
I feel personally obliged to help reduce the impact of climate change \\
I feel adaptation has become necessary for all of us \\
\hline Perceived Behavioral Control \\
If everyone takes action, we could reduce the impact of climate change \\
I have the ability to reduce the impact of climate change \\
I'm confident that I could contribute to reducing the impact of climate change \\
I'm able to contribute to reducing CO2 emissions \\
I'm able to contribute to reducing greenhouse gas emissions \\
\hline Intention \\
I am not willing to change my lifestyle to counteract global warming and climate change \\
I am willing to implement pro-environmental methods for my peers \\
It is my responsibility to encourage my neighbors to adopt ways to counter climate change \\
I have made major efforts to adopt ways to counter climate change last year \\
I am willing to implement pro-environmental methods for my family \\
I'll do everything that can reduce the impact of climate change \\
\hline Pro-Environment Behavior
\end{tabular}

\section{Pro-Environmental Behavior}

I have changed/I will change to a more fuel efficient car

I use public transport

I try to recycle as much as possible

I have reduced the amount of waste I used to produce

I have installed low energy light bulbs

I turn off lights/fans/electrical appliances when not in use

Note: Attitude, Subjective Norms, Perceived Behavioral Control, Intention and Pro-Environmental Behavior represent the constructs of Theory of Planned Behavior model. 
Table A2. Section C of the Post-COVID-19 questionnaire.

\begin{tabular}{|c|c|c|}
\hline \multicolumn{3}{|c|}{ Section C-COVID } \\
\hline Construct & Measurement Items & Frequency \\
\hline \multirow[t]{5}{*}{$\mathrm{CC} 1$} & Please select the statement which best describes your opinion & \\
\hline & $\begin{array}{l}\text { In your opinion is there a relationship between COVID-19 and } \\
\text { climate change? }\end{array}$ & \\
\hline & $\square \mathrm{YES}$ & 194 \\
\hline & $\square \mathrm{NO}$ & 31 \\
\hline & ㅁI Don't Know & 14 \\
\hline \multirow[t]{4}{*}{$\mathrm{CC} 2$} & (only if you answered Yes) & \\
\hline & $\begin{array}{l}\text { What kind of relationship do you think exists between } \\
\text { COVID-19 and climate change? }\end{array}$ & \\
\hline & $\square$ Climate change is more urgent than COVID-19 & 21 \\
\hline & $\square$ Climate change is less urgent than COVID-19 & 173 \\
\hline \multirow[t]{4}{*}{ CC3 } & $\begin{array}{l}\text { In your opinion, what kind of effect has COVID-19 had on } \\
\text { climate change? }\end{array}$ & \\
\hline & $\begin{array}{l}\square \text { The COVID-19 lockdown showed us that by changing our } \\
\text { habits we can actually improve the climate problem. }\end{array}$ & 86 \\
\hline & $\begin{array}{l}\text { वThe COVID-19 showed us a preview of the devastating effects } \\
\text { we will suffer if we do not tackle the climate problem now. }\end{array}$ & 82 \\
\hline & ㅁI Don't Know & 71 \\
\hline
\end{tabular}

\section{References}

1. Doran, P.T.; Zimmerman, M.K. Examining the scientific consensus on climate change. Eos Trans. Am. Geophys. Union 2009, 90, 22-23. [CrossRef]

2. IPCC (The Intergovernmental Panel on Climate Change). Climate Change 2013: The Physical Science Basis. Contribution of Working Group I to the Fifth Assessment Report of the Intergovernmental Panel on Climate Change; Stocker, T.F., Qin, D., Plattner, G.-K., Tignor, M., Allen, S.K., Boschung, J., Nauels, A., Xia, Y., Bex, V., Midgley, P.M., Eds.; Cambridge University Press: Cambridge, UK; New York, NY, USA, 2013; 1535p.

3. Vlek, C.; Steg, L. Human behavior and environmental sustainability: Problems, driving forces, and research topics. J. Soc. Issues 2007, 63, 1-19. [CrossRef]

4. Brody, S.; Grover, H.; Vedlitz, A. Examining the willingness of Americans to alter behaviour to mitigate climate change. Clim. Policy 2012, 12, 1-22. [CrossRef]

5. Casaló, L.V.; Escario, J.-J. Heterogeneity in the association between environmental attitudes and pro-environmental behavior: A multilevel regression approach. J. Clean. Prod. 2018, 175, 155-163. [CrossRef]

6. Thondhlana, G.; Hlatshwayo, T.N. Pro-environmental behaviour in student residences at Rhodes University, South Africa. Sustainability 2018, 10, 2746. [CrossRef]

7. Stern, N. The Economics of Climate Change: The Stern Review; Cambridge University Press: Cambridge, UK, 2007; ISBN 978-0-521-70080-1.

8. Burgess, J.; Harrison, C.M.; Filius, P. Environmental communication and the cultural politics of environmental citizenship. Environ. Plan. Econ. Space 1998, 30, 1445-1460. [CrossRef]

9. Masud, M.M.; Akhtar, R.; Afroz, R.; Al-Amin, A.Q.; Kari, F.B. Pro-environmental behavior and public understanding of climate change. Mitig. Adapt. Strateg. Glob. Chang. 2015, 20, 591-600. [CrossRef]

10. Liberman, N.; Trope, Y. The Role of feasibility and desirability considerations in near and distant future decisions: A test of temporal construal theory. J. Pers. Soc. Psychol. 1998, 75, 5-18. Available online: https://doi.org/10.1037/0022-3514.75.1.5 (accessed on 15 December 2020). [CrossRef]

11. Liberman, N.; Trope, Y.; Stephan, E. Psychological distance. In Social Psychology: Handbook of Basic Principles; Kruglanski, A.W., Higgins, E.T., Eds.; The Guilford Press: New York, NY, USA, 2007; pp. 353-381. 
12. Maiella, R.; La Malva, P.; Marchetti, D.; Pomarico, E.; Di Crosta, A.; Palumbo, R.; Cetara, L.; Di Domenico, A.; Verrocchio, M.C. The psychological distance and climate change: A systematic review on the mitigation and adaptation behaviors. Front. Psychol. 2020, 11. [CrossRef]

13. Patz, J.A.; Daszak, P.; Tabor, G.M.; Aguirre, A.A.; Pearl, M.; Epstein, J.; Wolfe, N.D.; Kilpatrick, A.M.; Foufopoulos, J.; Molyneux, D.; et al. Unhealthy Landscapes: Policy Recommendations on Land Use Change and Infectious Disease Emergence. Environ. Health Perspect. 2004, 112, 1092-1098. [CrossRef]

14. Patz, J.A.; Martens, W.J.; Focks, D.A.; Jetten, T.H. Dengue fever epidemic potential as projected by general circulation models of global climate change. Environ. Health Perspect. 1998, 106, 147-153. [CrossRef]

15. Allen, T.; Murray, K.A.; Zambrana-Torrelio, C.; Morse, S.S.; Rondinini, C.; Di Marco, M.; Breit, N.; Olival, K.J.; Daszak, P. Global hotspots and correlates of emerging zoonotic diseases. Nat. Commun. 2017, 8, 1124. [CrossRef] [PubMed]

16. Perkins, K.M.; Munguia, N.; Ellenbecker, M.; Moure-Eraso, R.; Velazquez, L. COVID-19 pandemic lessons to facilitate future engagement in the global climate crisis. J. Clean. Prod. 2020, 125178. [CrossRef] [PubMed]

17. Ecker, U.K.H.; Butler, L.H.; Cook, J.; Hurlstone, M.J.; Kurz, T.; Lewandowsky, S. Using the COVID-19 economic crisis to frame climate change as a secondary issue reduces mitigation support. J. Environ. Psychol. 2020, 70, 101464. [CrossRef] [PubMed]

18. Urban, J.; Kohlova, M.B. The COVID-19 crisis diminishes neither pro-evnvironmental motivation nor pro-environmental behavior: A panel study. Psyarxiv 2020. [CrossRef]

19. Kollmuss, A.; Agyeman, J. Mind the Gap: Why do people act environmentally and what are the barriers to pro-environmental behavior? Environ. Educ. Res. 2002, 8, 239-260. [CrossRef]

20. Pisano, I.; Lubell, M. Environmental behavior in cross-national perspective: A multilevel analysis of 30 countries. Environ. Behav. 2015. [CrossRef]

21. Gkargkavouzi, A.; Halkos, G.; Matsiori, S. Environmental behavior in a private-sphere context: Integrating theories of planned behavior and value belief norm, self-identity and habit. Resour. Conserv. Recycl. 2019, 148, 145-156. [CrossRef]

22. Li, D.; Zhao, L.; Ma, S.; Shao, S.; Zhang, L. What influences an individual's pro-environmental behavior? A literature review. Resour. Conserv. Recycl. 2019, 146, 28-34. [CrossRef]

23. Sidique, S.F.; Lupi, F.; Joshi, S.V. The effects of behavior and attitudes on drop-off recycling activities. Resour. Conserv. Recycl. 2010, 54, 163-170. [CrossRef]

24. Graham-Rowe, E.; Jessop, D.C.; Sparks, P. Predicting household food waste reduction using an extended theory of planned behaviour. Resour. Conserv. Recycl. 2015, 101, 194-202. [CrossRef]

25. Botetzagias, I.; Dima, A.-F.; Malesios, C. Extending the Theory of Planned Behavior in the context of recycling: The role of moral norms and of demographic predictors. Resour. Conserv. Recycl. 2015, 95, 58-67. [CrossRef]

26. Eagly, A.H.; Chaiken, S. The Psychology of Attitudes; Harcourt Brace Jovanovich College Publishers: Orlando, FL, USA, 1993; 794p, ISBN 978-0-15-500097-1.

27. Vining, J.; Ebreo, A. Predicting Recycling Behavior from Global and Specific Environmental Attitudes and Changes in Recycling Opportunities1. J. Appl. Soc. Psychol. 1992, 22, 1580-1607. [CrossRef]

28. Schwartz, S.H. Awareness of consequences and the influence of moral norms on interpersonal behavior. Sociometry 1968, 31, 355-369. [CrossRef]

29. Stern, P.C. Information, Incentives, and Pro-environmental Consumer Behavior. Available online: https: //link.springer.com/article/10.1023/A:1006211709570 (accessed on 4 December 2020).

30. Ajzen, I. From Intentions to Actions: A Theory of Planned Behavior. In Action Control: From Cognition to Behavior; Kuhl, J., Beckmann, J., Eds.; SSSP Springer Series in Social Psychology; Springer: Berlin/Heidelberg, Germany, 1985; pp. 11-39. ISBN 978-3-642-69746-3.

31. Ajzen, I.; Fishbein, M. Attitude-behavior relations: A theoretical analysis and review of empirical research. Psychol. Bull. 1977, 84, 888-918. [CrossRef]

32. Ajzen, I.; Madden, T.J. Prediction of goal-directed behavior: Attitudes, intentions, and perceived behavioral control. J. Exp. Soc. Psychol. 1986, 22, 453-474. [CrossRef]

33. Fishbein, M.; Yzer, M.C. Using Theory to Design Effective Health Behavior Interventions. Commun. Theory 2003, 13, 164-183. [CrossRef]

34. Fishbein, M.; Ajzen, I. Predicting and Changing Behavior: The Reasoned Action Approach; Psychology Press: London, UK, 2010; Available online: https://doi.org/10.4324/9780203838020 (accessed on 24 July 2009). 
35. Si, H.; Shi, J.; Tang, D.; Wen, S.; Miao, W.; Duan, K. Application of the Theory of Planned Behavior in Environmental Science: A Comprehensive Bibliometric Analysis. Int. J. Environ. Res. Public Health 2019, 16, 2788. [CrossRef]

36. Chen, M.-F. Extending the theory of planned behavior model to explain people's energy savings and carbon reduction behavioral intentions to mitigate climate change in Taiwan-moral obligation matters. J. Clean. Prod. 2016, 112, 1746-1753. [CrossRef]

37. De Leeuw, A.; Valois, P.; Ajzen, I.; Schmidt, P. Using the theory of planned behavior to identify key beliefs underlying pro-environmental behavior in high-school students: Implications for educational interventions. J. Environ. Psychol. 2015, 42, 128-138. [CrossRef]

38. Shafiei, A.; Maleksaeidi, H. Pro-environmental behavior of university students: Application of protection motivation theory. Glob. Ecol. Conserv. 2020, 22, e00908. [CrossRef]

39. Yazdanpanah, M.; Forouzani, M. Application of the Theory of Planned Behaviour to predict Iranian students' intention to purchase organic food. J. Clean. Prod. 2015, 107, 342-352. [CrossRef]

40. Vicente-Molina, M.A.; Fernández-Sainz, A.; Izagirre-Olaizola, J. Does gender make a difference in pro-environmental behavior? The case of the Basque Country University students. J. Clean. Prod. 2018, 176, 89-98. [CrossRef]

41. Hair, J.F.; Ringle, C.M.; Sarstedt, M. PLS-SEM: Indeed a Silver Bullet. J. Mark. Theory Pract. 2011, 19, $139-152$. [CrossRef]

42. Lei, P.-W.; Wu, Q. Introduction to Structural Equation Modeling: Issues and Practical Considerations. Educ. Meas. Issues Pract. 2007, 26, 33-43. [CrossRef]

43. Sarstedt, M.; Ringle, C.M.; Henseler, J.; Hair, J.F. On the Emancipation of PLS-SEM: A Commentary on Rigdon (2012). Long Range Plan. 2014, 47, 154-160. [CrossRef]

44. Sharma, P.N.; Kim, K.H. A Comparison of PLS and ML Bootstrapping Techniques in SEM: A Monte Carlo Study. In New Perspectives in Partial Least Squares and Related Methods; Abdi, H., Chin, W.W., Esposito Vinzi, V., Russolillo, G., Trinchera, L., Eds.; Springer: New York, NY, USA, 2013; pp. 201-208.

45. Hair, J.F., Jr.; Sarstedt, M.; Hopkins, L.; Kuppelwieser, V.G. Partial least squares structural equation modeling (PLS-SEM): An emerging tool in business research. Eur. Bus. Rev. 2014, 26, 106-121. [CrossRef]

46. Reinartz, W.; Haenlein, M.; Henseler, J. An empirical comparison of the efficacy of covariance-based and variance-based SEM. Int. J. Res. Mark. 2009, 26, 332-344. [CrossRef]

47. Cronbach, L.J. Coefficient alpha and the internal structure of tests. Psychometrika 1951, 16, 297-334. [CrossRef]

48. Dijkstra, T.; Henseler, J. Consistent Partial Least Squares Path Modeling. Manag. Inf. Syst. Q. 2015, 39, 297-316. [CrossRef]

49. Henseler, J.; Ringle, C.M.; Sarstedt, M. A new criterion for assessing discriminant validity in variance-based structural equation modeling. J. Acad. Mark. Sci. 2015, 43, 115-135. [CrossRef]

50. Wetzels, M.; Odekerken-Schröder, G.; van Oppen, C. Using PLS path modeling for assessing hierarchical construct models: Guidelines and empirical illustration. MIS Q. 2009, 33, 177-195. [CrossRef]

51. Henseler, J.; Fassott, G. Testing Moderating Effects in PLS Path Models: An Illustration of Available Procedures. In Handbook of Partial Least Squares: Concepts, Methods and Applications; Esposito Vinzi, V., Chin, W.W., Henseler, J., Wang, H., Eds.; Springer Handbooks of Computational Statistics; Springer: Berlin/Heidelberg, Germany, 2010; pp. 713-735. ISBN 978-3-540-32827-8.

52. Baron, R.M.; Kenny, D.A. The moderator-mediator variable distinction in social psychological research: Conceptual, strategic, and statistical considerations. J. Pers. Soc. Psychol. 1986, 51, 1173-1182. [CrossRef]

53. Tilikidou, I.; Delistavrou, A. Pro-Environmental Purchasing Behaviour during the economic crisis. Mark. Intell. Plan. 2014, 32, 160-173. [CrossRef]

54. Ivlevs, A. Adverse welfare shocks and pro-environmental behavior: Evidence from the global economic crisis. Rev. Income Wealth 2019, 65, 293-311. [CrossRef]

55. Temple, J. We Need Economic Relief Now. Climate Policy Can Come Later. Available online: https://www.technologyreview.com/2020/03/24/950341/coronavirus-economic-stimulus-climatepolicy-clean-energy-covid19/ (accessed on 5 December 2020).

56. Botzen, W.; Duijndam, S.; van Beukering, P. Lessons for climate policy from behavioral biases towards COVID-19 and climate change risks. World Dev. 2021, 137, 105214. [CrossRef]

57. Ching, J.; Kajino, M. Rethinking air quality and climate change after COVID-19. Int. J. Environ. Res. Public Health 2020, 17, 5167. [CrossRef] 
58. Hepburn, C.; O'Callaghan, B.; Stern, N.; Stiglitz, J.; Zenghelis, D. Will COVID-19 fiscal recovery packages accelerate or retard progress on climate change? Oxf. Rev. Econ. Policy 2020, 36, S359-S381. [CrossRef]

59. Norouzi, N.; Zarazua de Rubens, G.; Choupanpiesheh, S.; Enevoldsen, P. When pandemics impact economies and climate change: Exploring the impacts of COVID-19 on oil and electricity demand in China. Energy Res. Soc. Sci. 2020, 68, 101654. [CrossRef]

60. Prideaux, B.; Thompson, M.; Pabel, A. Lessons from COVID-19 can prepare global tourism for the economic transformation needed to combat climate change. Tour. Geogr. 2020, 22, 667-678. [CrossRef]

61. Klenert, D.; Funke, F.; Mattauch, L.; O'Callaghan, B. Five lessons from COVID-19 for advancing climate change mitigation. Environ. Resour. Econ. 2020, 76, 751-778. [CrossRef]

62. Khan, Z.; Ludlow, D.; Loibl, W.; Soomro, K. ICT enabled participatory urban planning and policy development: The UrbanAPI project. Transform. Gov. People Process Policy 2014, 8, 205-229. [CrossRef]

63. Eshkol, B.; Eshkol, A. Participatory planning in Israel: From theory to practice. J. Place Manag. Dev. 2017, 10, 213-239. [CrossRef]

64. Wang, A.; Chan, E.H.W. The impact of power-geometry in participatory planning on urban greening. Urban For. Urban Green. 2020, 48, 126571. [CrossRef]

65. Armitage, C.J.; Conner, M. Efficacy of the Theory of Planned Behaviour: A meta-analytic review. Br. J. Soc. Psychol. 2001, 40, 471-499. [CrossRef]

66. Chao, Y.-L.; Lam, S.-P. Measuring responsible environmental behavior: Self-reported and other-reported measures and their differences in testing a behavioral model. Environ. Behav. 2011, 43, 53-71. [CrossRef]

Publisher's Note: MDPI stays neutral with regard to jurisdictional claims in published maps and institutional affiliations.

(C) 2020 by the authors. Licensee MDPI, Basel, Switzerland. This article is an open access article distributed under the terms and conditions of the Creative Commons Attribution (CC BY) license (http://creativecommons.org/licenses/by/4.0/). 